Review began 01/31/2022 Review ended 02/21/2022 Published 02/22/2022

() Copyright 2022

Shibata et al. This is an open access article distributed under the terms of the Creative Commons Attribution License CC-BY 4.0., which permits unrestricted use, distribution, and reproduction in any medium, provided the original author and source are credited.

\section{Use of Eltrombopag for the First Trimester Pregnancy Complicated with Refractory Idiopathic Thrombocytopenic Purpura: A Case Report and Literature Review}

\author{
Satoshi Shibata ${ }^{1}$, Takuya Misugi ${ }^{1}$, Takahiko Nakane $^{2}$, Masayuki Hino ${ }^{2}$, Daisuke Tachibana ${ }^{1}$ \\ 1. Obstetrics and Gynecology, Osaka City University Graduate School of Medicine, Osaka, JPN 2. Hematology, Osaka \\ City University Graduate School of Medicine, Osaka, JPN
}

Corresponding author: Takuya Misugi, misutaku1975@infoseek.jp

\begin{abstract}
Severe idiopathic thrombocytopenic purpura (ITP) is thought to occur in approximately one in 10,000 pregnancies and refractoriness for conventional treatment is life-threatening. We herein describe a pregnant case of refractory ITP successfully treated with eltrombopag, orally medicated thrombopoietin receptor agonist (TPO-RA). The patient was diagnosed with ITP at the age of 22 and corticosteroid, immune globulin treatments, or splenectomy was invalid. Eltrombopag was administered at $25 \mathrm{mg} / \mathrm{day}$ and the platelet count was maintained at $50-80 \times 10^{9} / \mathrm{L}$. At the age of 32 , she discontinued the medication out of fear of the possible adverse events of TPO-RA. She became pregnant and visited our hospital at the gestational age of 9th week with the result of a platelet count at $18 \times 10^{9} / \mathrm{L}$. Two weeks later, her platelet counts further decreased to $9 \times$ $10^{9} / \mathrm{L}$, and eltrombopag administration was resumed with $12.5 \mathrm{mg} /$ day after informed written consent. The platelet counts subsequently increased and were maintained between 30 and $90 \times 10^{9} / \mathrm{L}$. At 34 th gestational week, the dose of eltrombopag was increased to $25 \mathrm{mg} /$ day in preparation for delivery and the count increased to $123 \times 10^{9} / \mathrm{L}$ by the 38th gestational week. A healthy female infant weighing $2370 \mathrm{~g}$ was vaginally delivered by induced labor. Maternal blood loss was $0.4 \mathrm{~L}$ at delivery, and the newborn's platelet count was $173 \times 10^{9} / \mathrm{L}$ on the second day after birth and $174 \times 10^{9} / \mathrm{L}$ on the fifth day. The infant is neurologically and developmentally intact at 6 months of age. Regarding TPO-RA treatment for refractory ITP during pregnancy, only six pregnant cases including the present one treated with eltrombopag have been reported so far. This case is rare with reference to the use of eltrombopag for the first trimester and we increased the dose of eltrombopag at the gestational age of 34 in preparation for delivery and vaginal delivery was successful without platelet transfusion. Despite the very limited information on eltrombopag, its use might be a possible optional treatment for refractory ITP during pregnancy.
\end{abstract}

Categories: Obstetrics/Gynecology, Hematology, Therapeutics

Keywords: refractory thrombocytopenia, thrombopoietin receptor agonist, eltrombopag, pregnancy, idiopathic thrombocytopenic purpura

\section{Introduction}

Idiopathic thrombocytopenic purpura (ITP) is an autoimmune disease characterized by both increased platelet destruction and reduced platelet production [1]. Severe ITP (platelets count less than $50 \times 10^{9} / \mathrm{L}$ ) is one of the most challenging diseases during pregnancy and is thought to occur in approximately one in 10,000 pregnancies [2]. Furthermore, refractory ITP cases for conventional first-line treatment, i.e., corticosteroids, intravenous immunoglobulin, and splenectomy are relatively rare in the obstetrical practice, however, this condition is life-threatening for the pregnant woman [3]. Recent works of literature on thrombopoietin receptor agonist (TPO-RA) report its efficacy and safety for refractory ITP in a relatively large population and randomized studies [4], however, its use during pregnancy and the effect on the neonatal outcome is limited. We herein describe a pregnant case of refractory ITP successfully treated with orally medicated TPO-RA (eltrombopag) and we also review the literature of its use during pregnancy.

\section{Case Presentation}

The patient was diagnosed with ITP after thrombocytopenia was discovered by an occasional medical examination at the age of 22 . The test of Helicobacter pylori was negative and corticosteroid and immune globulin treatments did not increase platelet counts. At the age of 24 , splenectomy was undergone with platelet transfusion, however, platelet count gradually decreased after a few years. Eltrombopag was administered $25 \mathrm{mg} /$ day and the platelet was maintained at 50-80 $\times 10^{9} / \mathrm{L}$. At the age of 32 , she married and discontinued the medication by her own request for the fear of the teratology of TPO-RA. She became pregnant after 9 months and visited our department at the gestational age of 9th week with the result of platelet count $18 \times 10^{9} / \mathrm{L}$. Two weeks later platelet count further decreased to $9 \times 10^{9} / \mathrm{L}$ and eltrombopag 
administration was resumed with $12.5 \mathrm{mg} /$ day after informed written consent. The platelet count increased and was maintained between 30 and $90 \times 10^{9} / \mathrm{L}$ (Figure 1). At 34th gestational week, the dose of eltrombopag was increased to $25 \mathrm{mg} /$ day in preparation for delivery and platelet increased to $123 \times 10^{9} / \mathrm{L}$ at 38 th gestational week. A healthy female infant weighing $2370 \mathrm{~g}$ was vaginally delivered by induced labor. Maternal blood loss was $0.4 \mathrm{~L}$ at delivery and the newborn's platelet count was $173 \times 10^{9} / \mathrm{L}$ on the second day after birth and $174 \times 10^{9} / \mathrm{L}$ on the fifth day. Breastfeeding was not recommended as the effects of eltrombopag on the neonate are unknown. The maternal platelet count after delivery was $119 \times 10^{9} / \mathrm{L}$ and eltrombopag was reduced to $12.5 \mathrm{mg} / \mathrm{day}$. The patient was discharged from our hospital with her baby on the fifth postpartum day. The infant is neurologically and developmentally intact so far at the age of 6 months.

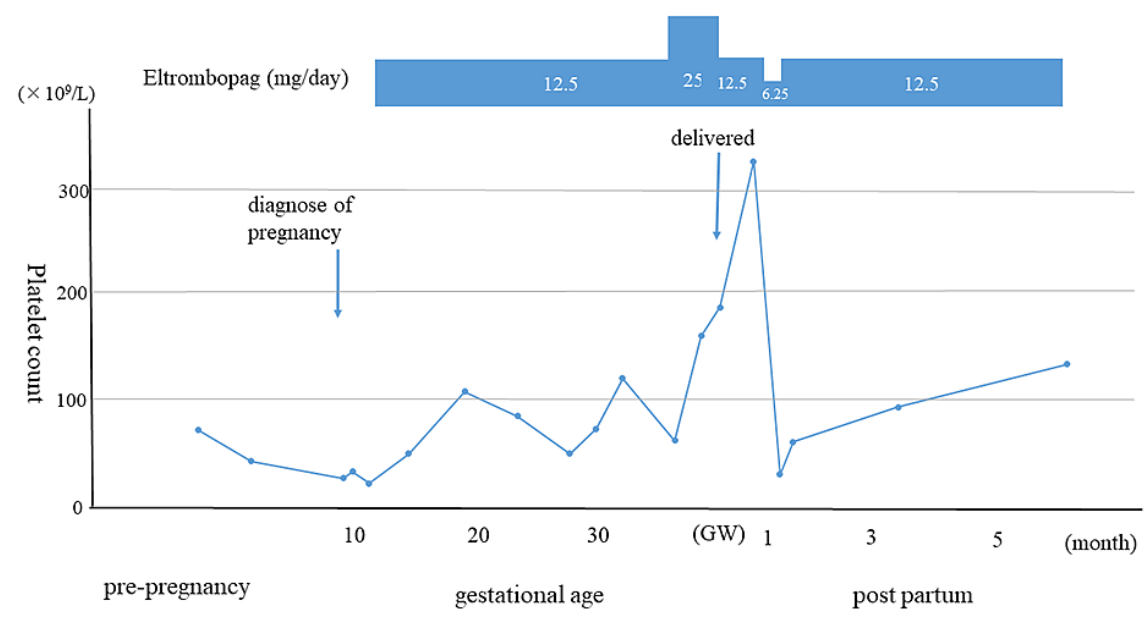

\section{FIGURE 1: The transition of platelet count before, during, and after} pregnancy.

In this pregnancy, she first administered eltrombopag at 11 th gestational week. Platelet counts were kept above 30 $\times 10^{9} / \mathrm{L}$ during pregnancy. In preparation for the delivery, the dose of eltrombopag was increased to $25 \mathrm{mg} /$ day at the 36 th gestational week.

\section{Discussion}

TPO-RA stimulates TPO-receptor of bone marrow to increase the production of platelets and two TPO receptor agonists have been approved: romiplostim and eltrombopag. Romiplostim, a peptide with molecular weight of 59,085 Dalton, is administered subcutaneously binding to the extracellular TPO receptor, while eltrombopag, a non-peptide with molecular weight of 546 Dalton, is administered orally binding to a transmembrane site of the TPO receptor, both of them promote the differentiation and proliferation of megakaryocyte and increase the production of platelets [5,6]. Romiplostim or eltrombopag have been investigated in several randomized controlled trials involving adult and pediatric ITP patients [79], and meta-analysis reports show that TPO receptor agonists with ITP patients were an effective secondline treatment option for primary ITP patients, in whom at least one previous therapy has failed [10]. Among patients treated with romiplostim, an average of $75 \%$ showed a significant response in platelet counts, whereas $69 \%$ of patients responded with eltrombopag [11]. An initial response to TPO-RA commonly appears within 1 to 2 weeks. If one TPO-RA agent is ineffective, switching to the other leads to a platelet response in up to $50 \%$ of patients $[11,12]$.

In this case, her platelet count decreased to $9 \times 10^{9} / \mathrm{L}$ and we administered eltrombopag at the gestational age of 11 weeks to avoid frequent platelet transfusion. Regarding TPO-RA treatment during pregnancy, however, there is no international consensus on the optimal treatment [13] and the use of eltrombopag is quite limited. As far as we researched, only five pregnant cases treated with eltrombopag have been reported. The summary of the cases including the present case is shown in Table 1. Two cases were complicated other than ITP. One thrombocytopenia case accompanied by systemic lupus erythematosus (SLE) was firstly reported by Alkaabi et al. [14]. The case did not respond to eltrombopag $50 \mathrm{mg} / \mathrm{day}$, later increased to $75 \mathrm{mg} /$ day, and further switched to romiplostim, which showed a significant increase of platelets [14]. Favier et al. medicated eltrombopag from 36th gestational week to a case complicated with autosomal dominant thrombocytopenia, i.e., $M Y H 9$-related disease, and successful platelet increase was observed [15]. Four cases of ITP, including the present case, were treated with eltrombopag (cases 3-6) [1618]. Case 3 showed slight platelet increase necessitated with platelet transfusion for vaginal delivery and case 4 achieved platelet increase over $60 \times 10^{9} / \mathrm{L}$, however, platelet count fell to $19 \times 10^{9} / \mathrm{L}$ at 36 th week of 


\section{Cureus}

gestation, where preeclampsia could not be ruled out from the cause of underlying pathology [16], and the patient subsequently needed platelet transfusion for delivery. Sufficient platelet increases with eltrombopag were observed in cases 4 and 6 (our case) [17]. In particular, we increased the dose of eltrombopag at the gestational age of 34 and vaginal delivery was succeeded without platelet transfusion. The impact of TPORA on the fetus is unknown due to no basic or clinical study being reported about the placental passage of TPO-RA. No neonate showed a congenital anomaly, although the two cases were medicated before pregnancy (case 5) or from the first trimester (case 6) [18]. Birth weights were relatively light-for-date, however, it is very difficult to mention whether it is resulted from the medication or maternal complication. No case showed maternal liver enzyme elevation or abnormal platelet count including thrombocytosis of the neonates.

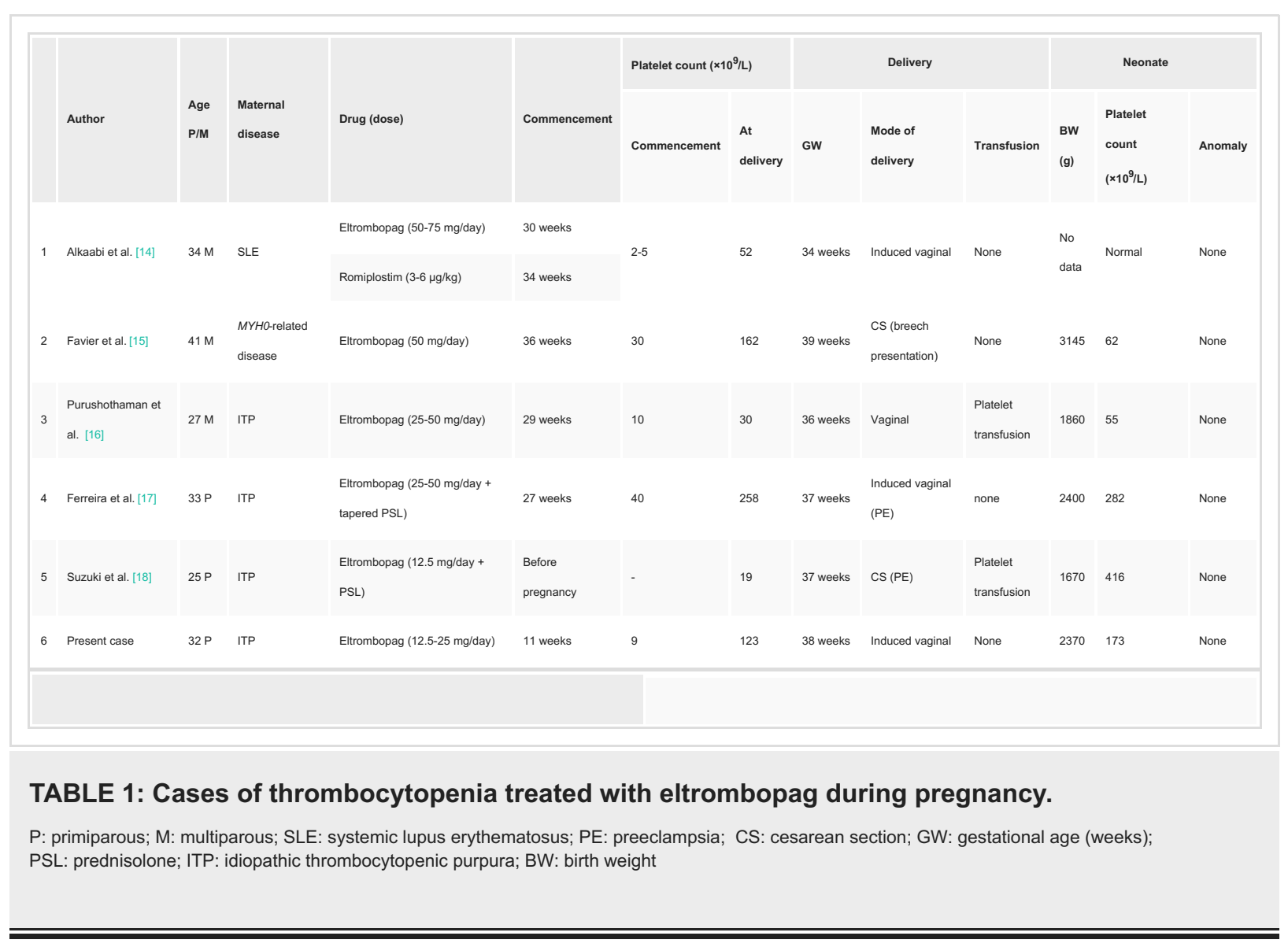

A threshold for initiation of treatment in the non-pregnant condition is recommended platelet count below $20 \times 10^{9} / \mathrm{L}$, even in the absence of bleeding, since severe bleeding events such as intracerebral hemorrhage might occur at not low frequency [19]. Raising the platelet count is recommended in cases with comorbidities, older age, and exposure to antiplatelet or anticoagulant drugs [19]. Owing to the lack of evidence-based guidelines, empirical suggestion recommends the maintenance of the platelet count above $20 \times 10^{9} / \mathrm{L}$ to $30 \times 10^{9} / \mathrm{L}$ during pregnancy [20]. In our case, her platelet counts were kept above $30 \times 10^{9} / \mathrm{L}$ during pregnancy by administering eltrombopag and successfully delivered without platelet transfusion.

\section{Conclusions}

Despite the very limited information of eltrombopag during pregnancy, we conclude as follows: first, four thrombocytopenia cases out of six cases refractory to previous medication responded to an increase in the platelet count; second, no congenital anomaly or abnormal hematological finding of neonatal blood was observed, including the two cases in which medication was already started before pregnancy or in the first trimester, despite the slight possible adverse effect for fetal growth. Further studies should be needed to elucidate the efficacy and safety of eltrombopag during pregnancy to improve maternal and neonatal outcomes.

\section{Additional Information}

\section{Disclosures}

Human subjects: Consent was obtained or waived by all participants in this study. Conflicts of interest: In compliance with the ICMJE uniform disclosure form, all authors declare the following: Payment/services info: All authors have declared that no financial support was received from any organization for the 
submitted work. Financial relationships: All authors have declared that they have no financial relationships at present or within the previous three years with any organizations that might have an interest in the submitted work. Other relationships: All authors have declared that there are no other relationships or activities that could appear to have influenced the submitted work.

\section{References}

1. Nugent D, McMillan R, Nichol JL, Slichter SJ: Pathogenesis of chronic immune thrombocytopenia: increased platelet destruction and/or decreased platelet production. Br J Haematol. 2009, 146:585-96. 10.1111/j.13652141.2009.07717.x

2. Care A, Pavord S, Knight M, Alfirevic Z: Severe primary autoimmune thrombocytopenia in pregnancy: a national cohort study. BJOG. 2018, 125:604-12. 10.1111/1471-0528.14697

3. Fullerton G, Danielian PJ, Bhattacharya S: Outcomes of pregnancy following postpartum haemorrhage. BJOG. 2013, 120:621-7. 10.1111/1471-0528.12120

4. Imbach P, Crowther M: Thrombopoietin-receptor agonists for primary immune thrombocytopenia . N Engl J Med. 2011, 365:734-41. 10.1056/NEJMct1014202

5. Erhardt JA, Erickson-Miller CL, Aivado M, Abboud M, Pillarisetti K, Toomey JR: Comparative analyses of the small molecule thrombopoietin receptor agonist eltrombopag and thrombopoietin on in vitro platelet function. Exp Hematol. 2009, 37:1030-7. 10.1016/j.exphem.2009.06.011

6. Cheng G, Saleh MN, Marcher C, et al.: Eltrombopag for management of chronic immune thrombocytopenia (RAISE): a 6-month, randomised, phase 3 study. Lancet. 2011, 377:393-402. 10.1016/S0140-6736(10)609592

7. Tarantino MD, Bussel JB, Blanchette VS, et al.: Romiplostim in children with immune thrombocytopenia: a phase 3, randomised, double-blind, placebo-controlled study. Lancet. 2016, 388:45-54. 10.1016/S01406736(16)00279-8

8. Grainger JD, Locatelli F, Chotsampancharoen T, et al.: Eltrombopag for children with chronic immune thrombocytopenia (PETIT2): a randomised, multicentre, placebo-controlled trial. Lancet. 2015, 386:1649-58. 10.1016/S0140-6736(15)61107-2

9. Bussel JB, Cheng G, Saleh MN, et al.: Eltrombopag for the treatment of chronic idiopathic thrombocytopenic purpura. N Engl J Med. 2007, 357:2237-47. 10.1056/NEJMoa073275

10. Elgebaly AS, Ashal GE, Elfil M, Menshawy A: Tolerability and efficacy of eltrombopag in chronic immune thrombocytopenia: meta-analysis of randomized controlled trials. Clin Appl Thromb Hemost. 2017, 23:92837. 10.1177/1076029616663849

11. Bidika E, Fayyaz H, Salib M, Memon AN, Gowda AS, Rallabhandi B, Cancarevic I: Romiplostim and eltrombopag in immune thrombocytopenia as a second-line treatment. Cureus. 2020, 12:e9920. 10.7759/cureus.9920

12. González-Porras JR, Mingot-Castellano ME, Andrade MM, et al.: Use of eltrombopag after romiplostim in primary immune thrombocytopenia. Br J Haematol. 2015, 169:111-6. 10.1111/bjh.13266

13. Eslick R, McLintock C: Managing ITP and thrombocytopenia in pregnancy. Platelets. 2020, 31:300-6. 10.1080/09537104.2019.1640870

14. Alkaabi JK, Alkindi S, Riyami NA, Zia F, Balla LM, Balla SM: Successful treatment of severe thrombocytopenia with romiplostim in a pregnant patient with systemic lupus erythematosus. Lupus. 2012, 21:1571-4. 10.1177/0961203312463621

15. Favier R, De Carne C, Elefant E, Lapusneanu R, Gkalea V, Rigouzzo A: Eltrombopag to treat thrombocytopenia during last month of pregnancy in a woman with MYH9-related disease: a case report. A A Pract. 2018, 10:10-2. 10.1213/XAA.0000000000000621

16. Purushothaman J, Puthumana KJ, Kumar A, Innah SJ, Gilvaz S: A case of refractory immune thrombocytopenia in pregnancy managed with elthrombopag. Asian J Transfus Sci. 2016, 10:155-8. 10.4103/0973-6247.177204

17. Ferreira IJ, Sousa F, Vasco EM, Areia AL, Moura JP, Carda J, Ribeiro L: Severe immune thrombocytopenia in pregnancy treated with Eltrombopag - A case report. J Gynecol Obstet Hum Reprod. 2018, 47:405-8. 10.1016/j.jogoh.2018.06.010

18. Suzuki N, Hiraga J, Hariyama Y, et al.: A low birth weight infant with no malformations delivered by a primary immune thrombocytopenia patient treated with eltrombopag. Int J Hematol. 2018, 108:109-11. 10.1007/s12185-017-2383-1

19. Provan D, Arnold DM, Bussel JB, et al.: Updated international consensus report on the investigation and management of primary immune thrombocytopenia. Blood Adv. 2019, 3:3780-817. 10.1182/bloodadvances.2019000812

20. Cines DB, Levine LD: Thrombocytopenia in pregnancy. Hematol Am Soc Hematol Educ Program. 2017, 2017:144-51. 10.1182/asheducation-2017.1.144 